\title{
Reliability Analysis of Unrepairable Systems with Uncertain Lifetimes
}

\author{
Ying Liu, Xiaozhong Li ${ }^{*}$ and Congcong Xiong \\ College of Computer Sciences and Information Engineering \\ Tianjin University of Science and Technology, Tianjin 300072, China \\ liu@tust.edu.cn,lixz@tust.edu.cn,xiongcc@tust.edu.cn
}

\begin{abstract}
The topic of unrepairable system is an important content in system reliability theory. There are many reasons cannot be repaired, some because of technical reasons, cannot repair, some because of economic reasons, not worth to repair, and some because of making repairable system simplification. So it is essential to pay attention to unrepairable systems. In this paper, the lifetimes of unrepairable systems are considered as uncertain variables. Based on that, the fundamental mathematical models of series systems, parallel systems, series-parallel systems and parallel-series systems are established, respectively. Furthermore, we make reliability analysis of above four unrepairable systems, respectively. Some numerical examples are also given for illustration.
\end{abstract}

Keywords: Reliability; Mean time to failure; uncertain variable; Unrepairable system

\section{Introduction}

The unrepairable systems reliability theory has been successfully used for solving various reliability problems, in which the lifetimes of systems are assumed to be random variables and the system behavior can be fully characterized by probability theory. For example, Barlow and Proschan [1] mainly considered the mathematical models and methods directed toward the solutions of problems of components or systems. Barlow and Proschan [2] concentrated on probabilistic aspects of reliability theory. Khalil [16] considered several shut-off rules for series systems performance, and calculated limiting system availability under these shut-off rules. Osaki et al. [27] considered two models of two-unit nonindependent series system. Chao and $\mathrm{Fu}$ [7] studied the reliability of general series system and showed that the reliability of the system tended to a constant under certain regularity conditions. Chung [9] presented a reliability and availability of a series repairable system with multiple failures. Gurov and Utkin [12] proposed a new method to compute two-sided bounds for time-dependent availability of repairable series systems by arbitrary distributed time to failure and time to repair. Goel et al. [11] investigated a twounits (non-identical) parallel system and gave various state probabilities along with steady-state characteristics of the system. Sridharan and Mohanavadivu [28] presented three models with common cause failure and human error analysis of a two non-identical unit parallel system. Li et al. [18] considered the unavailability of a two-unit parallel system with one traveling repair person and common statistically independent exponential unit life lengths. Chhillar et al. [8] designed with an object to determine reliability measures of a parallel system of two identical units with priority to maintenance over repair subjected to random shocks.

Xiaozhong $\mathrm{Li}$ is the corresponding author. 
Although the traditional reliability theory has been proved to be effective in many cases, using probability method in engineering problems needs to have three basic premises: firstly, the events should be clearly defined; secondly, there should exist a large number of samples; and thirdly, the samples should have the probability of repetition. If one of the three premises does not hold, using probability theory to deal with the reliability problems may have certain limitations. Beyond that, the lifetimes of systems or components sometimes be characterized subjectively. Therefore, several researchers have paid attention to applying the fuzzy sets theory to reliability analysis. For instance, Kaufmann [15] first used fuzzy theory in reliability engineering in 1975. Cai et al. [3-6] introduced various forms of fuzzy reliability theories, including profust reliability theory, posbist reliability theory and posfust reliability theory. Utkin and Gurov [30] proposed a general approach on the basis of a system of functional equations according to Cai's theory. Huang [14] developed the fundamental calculation formulas of fuzzy reliability and established the fuzzy reliability models of unrepairable systems. In Liu et al. [23], reliability and performance assessment for fuzzy multi-state elements were considered. Zhang et al. [31] considered a fuzzy age-dependent replacement policy, in which the lifetimes of components were treated as fuzzy variables. Ding and Lisnianski [10] considered a multi-state system where performance rates and corresponding state probabilities were presented as fuzzy values. Liu et al. [26] gave reliability analysis of unrepairable systems by using fuzzy theory. Liu et al. [25] considered two dependent components, in which the parameters in joint survival probability were assumed to be fuzzy variables.

Although fuzzy theory had been widely applied, Liu [19] found that some kinds of uncertainty cannot be modeled by randomness nor fuzziness. In order to deal with this type of uncertainty, Liu [19] founded an uncertainty theory. Uncertainty theory has been used in many fields, such as Han et al. [13], Li and Liu [17], Tian et al. [29]. But just a few contributions showed that the uncertainty theory had been used in reliability analysis. For example, Liu [22] discussed the tool of uncertain reliability analysis. Liu et al. [24] considered the states of components and systems as uncertain variables, then defined the uncertain coherent system and proposed its structural properties. So the aim of this paper is to make reliability analysis of unrepairable systems under the framework of uncertainty theory.

The rest of this paper is organized as follows. In Section 2, we recall some basic concepts on uncertainty theory. In Section 3, we establish the fundamental mathematical models of uncertain unrepairable systems, including series systems, parallel systems, series-parallel systems and parallel-series systems. Furthermore, the expressions of reliability and MTTF for the four systems are given, respectively. Some examples are also presented to illustrate how to calculate the reliability and MTTF of given unrepairable systems. Section 4 draws some conclusions.

\section{Uncertainty Theory}

Let $\Gamma$ be a nonempty set and $\mathrm{L}$ a $\sigma$-algebra over $\Gamma$. Each element $\Lambda \in \mathrm{L}$ is called an event. Then a number $M\{\Lambda\}$ will be assigned to each event $\Lambda$ to indicate the belief degree with which we believe $\Lambda$ will happen. There is no doubt that the assignment is not arbitrary, and the uncertain measure $M$ must have certain mathematical properties. In order to rationally deal with belief degree, Liu [19] suggested the following three axioms:

Axiom 1. (Normality Axiom) $M\{\Lambda\}=1$ for the universal set $\Gamma$.

Axiom 2. (Duality Axiom) $\operatorname{M}\{\Lambda\}+M\left\{\Lambda^{C}\right\}=1$ for any event $\Lambda$. 
Axiom 3. (Subadditivity Axiom) For every countable sequence of events $\Lambda_{1}, \Lambda_{2}, \ldots$, we have

$$
\mathrm{M}\left\{\bigcup_{i=1}^{\infty} \Lambda_{i}\right\} \leq \sum_{i=1}^{\infty} \mathrm{M}\left\{\Lambda_{\mathrm{i}}\right\}
$$

Definition 1 (Liu [19]) The set function $M$ is called an uncertain measure if it satisfies the normality, duality and subadditivity axioms.

Definition 2 (Liu [19]) Let $\Gamma$ be a nonempty set, $\mathrm{L}$ a $\sigma$-algebra over $\Gamma$, and $\mathrm{M}$ an uncertain measure. Then the triplet $(\Gamma, \mathrm{L}, \mathrm{M})$ is called an uncertainty space.

Definition 3 (Liu [20]) Assume $\left(\Gamma_{\mathrm{k}}, \mathrm{L}_{k}, \mathrm{M}_{k}\right)$ are uncertainty spaces for $k=1,2, \ldots$ Let $\Gamma=\Gamma_{1} \times \Gamma_{2} \times \cdots, \mathrm{L}=\mathrm{L}_{1} \times \mathrm{L}_{2} \times \cdots$ and $\mathrm{M}=\mathrm{M}_{1} \times \mathrm{M}_{2} \times \cdots$ Then the triplet $(\Gamma, \mathrm{L}, \mathrm{M})$ is called a product uncertainty space.

Definition 4 (Liu [19]) An uncertain variable is a function $\xi$ from an uncertainty space $(\Gamma$, $\mathrm{L}, \mathrm{M})$ to the set of real numbers such that $\{\xi \in \mathrm{B}\}$ is an event for any Borel set $\mathrm{B}$.

Definition 5 (Liu [19]) An uncertain variable $\xi$ on the uncertainty space $(\Gamma, \mathrm{L}, \mathrm{M})$ is said to be positive if $\mathrm{M}\{\xi \leq 0\}=0$.

Definition 6 (Liu [19]) The uncertainty distribution $\Phi$ of an uncertain variable $\xi$ is defined by

$$
\Phi(x)=\mathbf{M}\{\xi \leq x\}
$$

for any real number $\mathrm{x}$.

Definition 7 (Liu [19]) An uncertain variable $\xi$ is called zigzag if it has a zigzag uncertainty distribution

$$
\Phi(x)= \begin{cases}0, & \text { if } \mathrm{x} \leq \mathrm{a} \\ (\mathrm{x}-\mathrm{a}) / 2(\mathrm{~b}-\mathrm{a}), & \text { if } \mathrm{a} \leq \mathrm{x} \leq \mathrm{b} \\ (\mathrm{x}+\mathrm{c}-2 \mathrm{~b}) / 2(\mathrm{c}-\mathrm{b}), & \text { if } \mathrm{b} \leq \mathrm{x} \leq \mathrm{c} \\ 1, & \text { if } \mathrm{x} \geq \mathrm{c},\end{cases}
$$

denoted by $\mathrm{Z}$ (a, b, c), where $\mathrm{a}, \mathrm{b}, \mathrm{c}$ are real numbers with $\mathrm{a}<\mathrm{b}<\mathrm{c}$.

Definition 8 (Liu [20]) The uncertain variables $\xi_{1}, \xi_{2}, \ldots, \xi_{m}$ are said to be independent if

$$
\mathbf{M}\left\{\bigcap_{i=1}^{m}\left\{\xi_{i} \in \mathrm{B}_{i}\right\}\right\}=\bigwedge_{i=1}^{m} \mathrm{M}\left\{\xi_{i} \in \mathrm{B}_{i}\right\}
$$

for any Borel sets $\mathrm{B}_{1}, \mathrm{~B}_{2}, \ldots, \mathrm{B}_{\mathrm{m}}$.

Theorem 1 (Liu [20]) The uncertain variables $\xi_{1}, \xi_{2}, \ldots, \xi_{m}$ are independent if and only if

$$
\mathrm{M}\left\{\bigcup_{i=1}^{m}\left\{\xi_{i} \in \mathrm{B}_{i}\right\}\right\}={\underset{i=1}{\mathrm{~V}}}_{\mathrm{V}} \mathrm{M}\left\{\xi_{i} \in \mathrm{B}_{i}\right\}
$$

for any Borel sets $B_{1}, B_{2}, \ldots, B_{m}$. 
Definition 9 (Liu [19]) Let $\xi$ be an uncertain variable. Then the expected value of $\xi$ is defined by

$$
\mathrm{E}[\mathrm{X}]=\int_{0}^{+\infty} \mathrm{M}\{\xi \geq x\} \mathrm{dx}-\int_{-\infty}^{0} \mathrm{M}\{\xi \leq x\} \mathrm{dx}
$$

provided that at least one of the two integrals is finite.

Theorem 2 (Liu [21]) Let $\xi$ be an uncertain variable with uncertainty distribution $\Phi$. Then

$$
\mathrm{E}[\mathrm{X}]=\int_{-\infty}^{+\infty} x \mathrm{~d} \Phi(x)
$$

\section{Reliability Analysis of Unrepairable Systems with Uncertain Lifetimes}

In this section, we first define the reliability and MTTF of unrepairable systems with uncertain lifetimes. Then the reliability and MTTF of uncertain series systems, parallel systems, series-parallel systems, parallel-series systems are discussed, respectively.

Consider the lifetime of an unrepairable system as a positive uncertain variable $\mathrm{X}$ on the uncertain space $(\Gamma, \mathrm{L}, \mathrm{M})$. We propose the following two definitions.

Definition 10 The reliability of the unrepairable system at time $t$ is defined by

$$
\mathrm{R}(\mathrm{t})=\mathrm{M}\{\mathrm{X}>\mathrm{t}\} \text {. }
$$

Definition 11 The MTTF of the unrepairable system is defined by

$$
\mathrm{MTTF}=\int_{0}^{+\infty} R(\mathrm{t}) \mathrm{dt} .
$$

\subsection{Reliability Analysis of Unrepairable Series Systems with Uncertain Lifetimes}

Consider a series system consisting of $n$ independent components, see Figure 1. Let $X_{i}$ be the uncertain lifetime of component $i$ defined on the uncertainty space $\left(\Gamma_{i}, L_{i}, M_{i}\right)$, $\mathrm{i}=1,2, \ldots, \mathrm{n}$. The lifetime of the series system can be expressed by $\mathrm{X}=\min \left\{\mathrm{X}_{1}, \mathrm{X}_{2}, \ldots, \mathrm{X}_{\mathrm{n}}\right\}$, which is also an uncertain variable on the product uncertainty space $(\Gamma, \mathrm{L}, \mathrm{M})$, where $\Gamma=\Gamma_{1} \times \Gamma_{2} \times \cdots \times \Gamma_{n}, \quad \mathrm{~L}=\mathrm{L}_{1} \times \mathrm{L}_{2} \times \cdots \times \mathrm{L}_{\mathrm{n}}$ and $\mathrm{M}=\mathrm{M}_{1} \wedge \mathrm{M}_{2} \wedge \cdots \wedge \mathrm{M}_{\mathrm{n}}$.

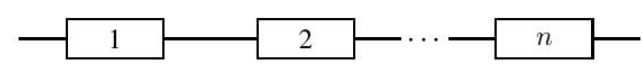

Figure 1. A Series System

Theorem 3 The reliability of the unrepairable series system is

$$
\mathrm{R}(\mathrm{t})=\hat{\mathrm{i}}_{\mathrm{i}}^{\mathrm{n}} \mathrm{M}\left\{\mathrm{X}_{\mathrm{i}}>\mathrm{t}\right\} \text {. }
$$

Proof. It follows from Definition 10 and Definition 8 that

$$
\begin{aligned}
\mathrm{R}(\mathrm{t}) & =\mathrm{M}\left\{\min \left\{\mathrm{X}_{1}, \mathrm{X}_{2}, \ldots, \mathrm{X}_{\mathrm{n}}\right\}>\mathrm{t}\right\} \\
& =\mathrm{M}\left\{\mathrm{X}_{1}>\mathrm{t}, \mathrm{X}_{2}>\mathrm{t}, \ldots, \mathrm{X}_{\mathrm{n}}>\mathrm{t}\right\} \\
& =\mathrm{M}\left\{\bigcap_{i=1}^{\mathrm{n}}\left\{\mathrm{X}_{i}>\mathrm{t}\right\}\right\}=\stackrel{\mathrm{n}}{\mathrm{n}=1} \mathrm{M}_{\wedge}\left\{X_{\mathrm{i}}>\mathrm{t}\right\} .
\end{aligned}
$$

The proof is complete. 
Theorem 4 The MTTF of the unrepairable series system is

$$
\mathrm{MTTF}=\hat{\mathrm{i}=1} \mathrm{n} \mathrm{E}\left[\mathrm{X}_{\mathrm{i}}\right] \text {. }
$$

Proof. It follows from Definition 11 and Theorem 3 that

$$
\begin{aligned}
\mathrm{MTTF} & =\int_{0}^{+\infty} \underset{\mathrm{i}=1}{\mathrm{n}} \mathrm{M}\left\{\mathrm{X}_{i}>\mathrm{t}\right\} \mathrm{dt} \\
& \leq \int_{0}^{+\infty} \mathrm{M}\left\{\mathrm{X}_{i}>\mathrm{t}\right\} \mathrm{dt}=\mathrm{E}\left[\mathrm{X}_{i}\right]
\end{aligned}
$$

Since $\mathrm{i}$ be an arbitrary number in $\{1,2, \ldots, \mathrm{n}\}$, so

$$
\mathrm{MTTF} \leq \wedge_{\mathrm{i}=1}^{\mathrm{n}} \mathrm{E}\left[\mathrm{X}_{i}\right] .
$$

On the other hand, for any $i \in\{1,2, \ldots, \mathrm{n}\}$,

holds, which implies that

$$
\hat{\mathrm{i}=1}_{\mathrm{n}}^{\mathrm{E}}\left[\mathrm{X}_{i}\right] \leq \mathrm{E}\left[\mathrm{X}_{i}\right]
$$

$$
\hat{\mathrm{i}=1}_{\mathrm{n}}^{\mathrm{n}} \mathrm{E}\left[\mathrm{X}_{i}\right] \leq \mathrm{E}[\mathrm{X}]=\mathrm{MTTF},
$$

where $X=\min \left\{X_{1}, X_{2}, \ldots, X_{n}\right\}$. It follows from equation (1) and (2) that

$$
\mathrm{MTTF}=\stackrel{\mathrm{n}}{\wedge} \mathrm{E}\left[\mathrm{X}_{\mathrm{i}}\right]
$$

The proof is complete.

Example 1 Suppose that the series system composed by two components. The lifetimes of component 1 and 2 are denoted by $X_{1}$ and $X_{2}$, which have zigzag uncertainty distribution $Z(1,2,3.5)$ and $Z(1.5,2.5,3)$, respectively. By Definition 6, we have

$$
\Phi_{1}(t)=\left\{\begin{array}{ll}
0, & \text { if } \mathrm{t} \leq 1 \\
\frac{t-1}{2}, & \text { if } 1 \leq \mathrm{t} \leq 2 \\
\frac{2 t-1}{6}, & \text { if } 2 \leq \mathrm{t} \leq 3.5 \\
1, & \text { if } \mathrm{t} \geq 3.5
\end{array} \text { and } \Phi_{2}(t)= \begin{cases}0, & \text { if } \mathrm{t} \leq 1.5 \\
\frac{t-1.5}{2}, & \text { if } 1.5 \leq \mathrm{t} \leq 2.5 \\
t-2, & \text { if } 2.5 \leq \mathrm{t} \leq 3 \\
1, & \text { if } \mathrm{t} \geq 3 .\end{cases}\right.
$$

It follows from Duality Axiom that

$$
\mathrm{M}\left\{\mathrm{X}_{1}>\mathrm{t}\right\}=1-\Phi_{1}(t)= \begin{cases}1, & \text { if } \mathrm{t} \leq 1 \\ \frac{3-t}{2}, & \text { if } 1 \leq \mathrm{t} \leq 2 \\ \frac{7-2 t}{6}, & \text { if } 2 \leq \mathrm{t} \leq 3.5 \\ 0, & \text { if } \mathrm{t} \geq 3.5\end{cases}
$$

and

$$
\mathrm{M}\left\{\mathrm{X}_{2}>\mathrm{t}\right\}=1-\Phi_{2}(t)= \begin{cases}1, & \text { if } \mathrm{t} \leq 1.5 \\ \frac{3.5-t}{2}, & \text { if } 1.5 \leq \mathrm{t} \leq 2.5 \\ 3-\mathrm{t}, & \text { if } 2.5 \leq \mathrm{t} \leq 3 \\ 0, & \text { if } \mathrm{t} \geq 3 .\end{cases}
$$

By Theorem 3, we have 


$$
R(t)=M\left\{X_{1}>t\right\} \wedge M\left\{X_{2}>t\right\} .
$$

The plot of the reliability of the series system can be shown in Figure 2.

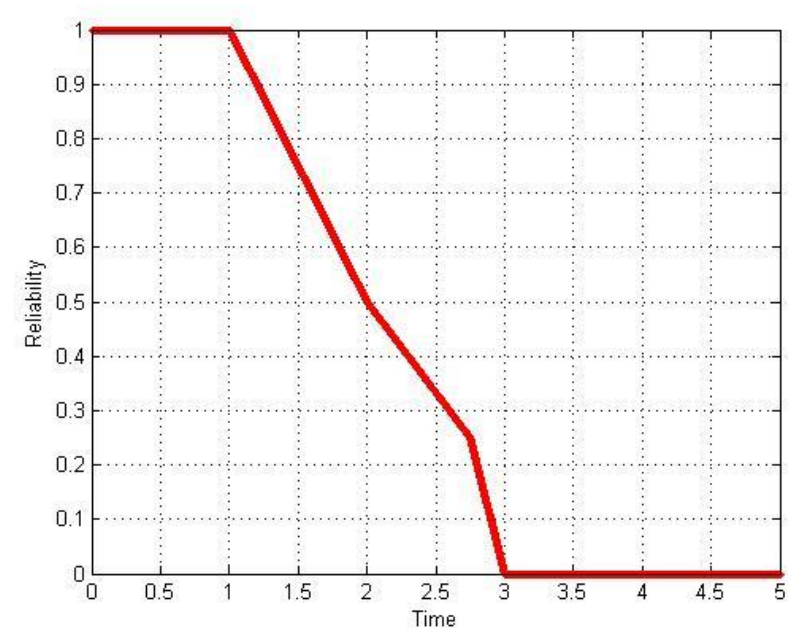

Figure 2. The Reliability of the Series System

By Theorem 2, we can arrive at

$$
\mathrm{E}\left[\mathrm{X}_{1}\right]=\int_{1}^{2} t d\left(\frac{t-1}{2}\right)+\int_{2}^{3.5} t d\left(\frac{2 t-1}{6}\right)=2.125
$$

and

$$
\mathrm{E}\left[\mathrm{X}_{2}\right]=\int_{1.5}^{2.5} t d\left(\frac{t-1.5}{2}\right)+\int_{2.5}^{3} t d(t-2)=2.375
$$

It follows from Theorem 4 that $\mathrm{MTTF}=\mathrm{E}\left[\mathrm{X}_{1}\right] \wedge \mathrm{E}\left[\mathrm{X}_{2}\right]=2.125$.

\subsection{Reliability Analysis of Unrepairable Parallel Systems with Uncertain Lifetimes}

Consider a parallel system consisting of $\mathrm{n}$ independent components, see Figure 3. Let $X_{i}$ be the lifetime of component $i$ on the uncertainty space $\left(\Gamma_{i}, L_{i}, M_{i}\right), i=1,2, \ldots, n$. The lifetime of the parallel system can be expressed by $X=\max \left\{X_{1}, X_{2}, \ldots, X_{n}\right\}$, which is also an uncertain variable on the product uncertainty space $(\Gamma, \mathrm{L}, \mathrm{M})$, where $\Gamma=\Gamma_{1} \times \Gamma_{2} \times \cdots \times \Gamma_{n}, L=L_{1} \times L_{2} \times \cdots \times L_{n}$ and $\mathrm{M}=\mathrm{M}_{1} \wedge \mathrm{M}_{2} \wedge \cdots \wedge \mathrm{M}_{\mathrm{n}}$.

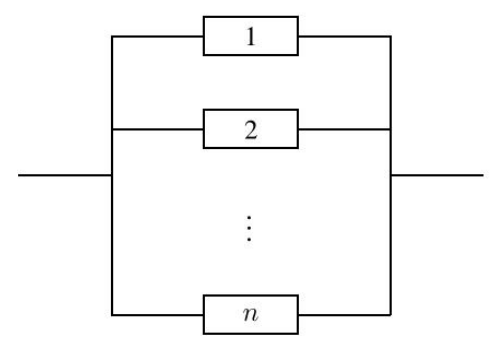

Figure 3. A Parallel System

Theorem 5 The reliability of the unrepairable parallel system is

$$
R(t)=\underset{i=1}{\vee} M\left\{X_{i}>t\right\} \text {. }
$$

Proof. It follows from Definition 10 and Theorem 1 that 


$$
\begin{aligned}
\mathrm{R}(\mathrm{t}) & =\mathrm{M}\left\{\max \left\{\mathrm{X}_{1}, \mathrm{X}_{2}, \ldots, \mathrm{X}_{\mathrm{n}}\right\}>\mathrm{t}\right\} \\
& =\mathrm{M}\left\{\bigcup_{i=1}^{n}\left\{\mathrm{X}_{\mathrm{i}}>\mathrm{t}\right\}\right\} \\
& =\underset{\mathrm{i}=1}{\mathrm{n}} \mathrm{M}\left\{\mathrm{X}_{\mathrm{i}}>\mathrm{t}\right\} .
\end{aligned}
$$

The proof is complete.

Theorem 6 The MTTF of the unrepairable parallel system is

$$
\mathrm{MTTF}=\underset{\mathrm{i}=1}{\mathrm{n}} \mathrm{E}\left[\mathrm{X}_{\mathrm{i}}\right] .
$$

Proof. It follows from Definition 11 and Theorem 5 that

$$
\begin{aligned}
\text { MTTF } & =\int_{0}^{+\infty} \underset{\mathrm{i}=1}{\vee} \mathrm{M}\left\{\mathrm{X}_{i}>\mathrm{t}\right\} \mathrm{dt} \\
& \geq \int_{0}^{+\infty} \mathrm{M}\left\{\mathrm{X}_{i}>\mathrm{t}\right\} \mathrm{dt}=\mathrm{E}\left[\mathrm{X}_{i}\right] .
\end{aligned}
$$

Since $i$ be an arbitrary number in $\{1,2, \ldots, n\}$, we have

$$
\operatorname{MTTF} \geq \underset{\mathrm{i}=1}{\mathrm{n}} \mathrm{E}\left[\mathrm{X}_{i}\right]
$$

Note that, for any $i \in\{1,2, \ldots, \mathrm{n}\}$,

$$
\mathrm{E}\left[\mathrm{X}_{i}\right] \leq \vee_{\mathrm{i}=1}^{\mathrm{n}} \mathrm{E}\left[\mathrm{X}_{i}\right]
$$

holds, so we have

$$
\mathrm{MTTF}=\mathrm{E}[\mathrm{X}] \leq \underset{\mathrm{i}=1}{\mathrm{n}} \mathrm{E}\left[\mathrm{X}_{i}\right],
$$

where $X=\max \left\{X_{1}, X_{2}, \ldots, X_{n}\right\}$. It follows from equation (3) and (4) that

$$
\mathrm{MTTF}=\underset{\mathrm{i}=1}{\mathrm{n}} \mathrm{E}\left[\mathrm{X}_{\mathrm{i}}\right]
$$

The proof is complete.

Example 2 Suppose that the parallel system composed by two components. The lifetimes of component 1 and 2 are denoted by $X_{1}$ and $X_{2}$, which have zigzag uncertainty distribution $Z(1,2,3.5)$ and $Z(1.5,2.5,3)$, respectively. The expressions of $\Phi_{1}(t), \Phi_{2}(t), \quad \mathrm{M}\left\{\mathrm{X}_{1}>\mathrm{t}\right\}, \quad \mathrm{M}\left\{\mathrm{X}_{2}>\mathrm{t}\right\}, \mathrm{E}\left[\mathrm{X}_{1}\right]$ and $\mathrm{E}\left[\mathrm{X}_{2}\right]$ can be referred to Example 1. Then by Theorem 5 , we have

$$
\mathrm{R}(\mathrm{t})=\mathrm{M}\left\{\mathrm{X}_{1}>\mathrm{t}\right\} \vee \mathrm{M}\left\{\mathrm{X}_{2}>\mathrm{t}\right\} .
$$

The plot of the reliability of the parallel system can be shown in Figure 4. 


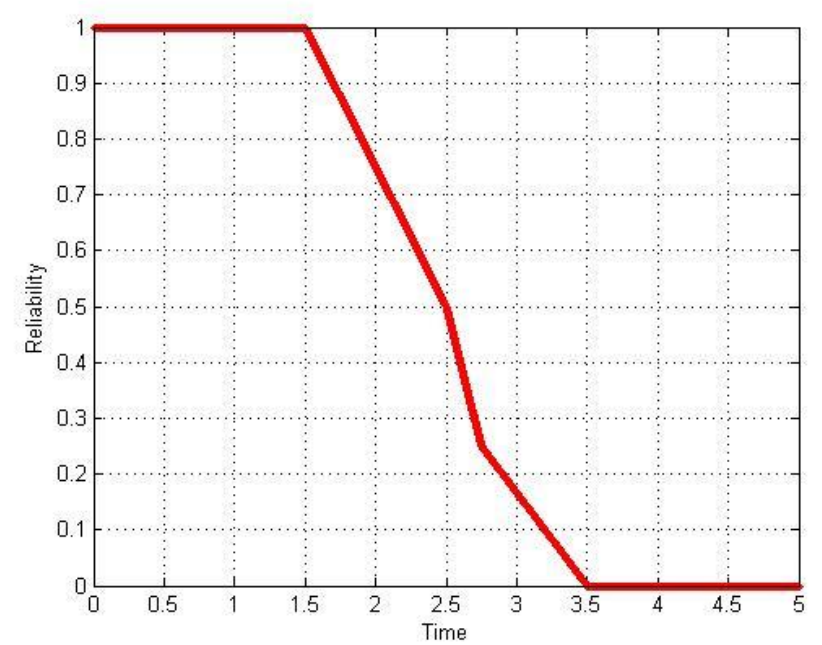

Figure 4. The Reliability of the Parallel System

It follows from Theorem 6 that

$$
\mathrm{MTTF}=\mathrm{E}\left[\mathrm{X}_{1}\right] \vee \mathrm{E}\left[\mathrm{X}_{2}\right]=2.375
$$

\subsection{Reliability Analysis of Unrepairable Series-Parallel Systems with Uncertain Lifetimes}

A series-parallel system is a series system of m subsystems, each subsystem composed of $n$ parallel components, see Figure 5. Let $X_{i j}$ be the lifetime of component $j$ in $i$ th subsystem, which is an uncertain variable on the uncertainty space $\left(\Gamma_{\mathrm{ij}}, \mathrm{L}_{\mathrm{ij}}, \mathrm{M}_{\mathrm{ij}}\right), \mathrm{i}=1,2, \ldots, \mathrm{m}, \mathrm{j}=1,2, \ldots, \mathrm{n}$.

Suppose $\mathrm{X}_{\mathrm{ij}}, \mathrm{i}=1,2, \ldots, \mathrm{m}, \mathrm{j}=1,2, \ldots, \mathrm{n}$ be independent mutually. The lifetime of the series-parallel system can expressed by $\mathrm{X}=\min _{1 \leq i \leq m}\left(\max _{1 \leq j \leq n} \mathrm{X}_{i j}\right)$, which is also an uncertain variable on the product uncertainty space $(\Gamma, \mathrm{L}, \mathrm{M})$, where $\quad \Gamma=\Gamma_{11} \times \Gamma_{12} \times \cdots \times \Gamma_{m n}, \quad \mathrm{~L}=\mathrm{L}_{11} \times \mathrm{L}_{12} \times \cdots \times \mathrm{L}_{\mathrm{mn}} \quad$ and $\mathrm{M}=\mathrm{M}_{11} \wedge \mathrm{M}_{12} \wedge \cdots \wedge \mathrm{M}_{\mathrm{mn}}$.

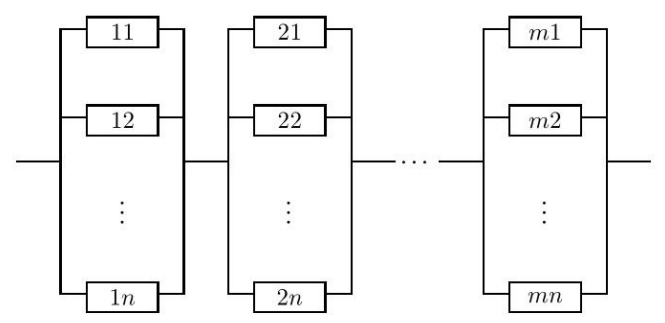

Figure 5. A Series-Parallel System

Theorem 7 The reliability of the series-parallel system is

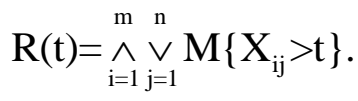

Theorem 8 The MTTF of the series-parallel system is 


$$
\mathrm{MTTF}=\wedge \underset{\mathrm{i}=1}{\mathrm{~m}} \underset{\mathrm{j}=1}{\mathrm{n}} \mathrm{E}\left[\mathrm{X}_{\mathrm{ij}}\right] .
$$

\subsection{Reliability Analysis of Unrepairable Parallel-Series Systems with Uncertain Lifetimes}

A parallel-series system is a parallel system of $\mathrm{m}$ subsystems, each subsystem composed of $n$ series components, see Figure 6 . Let $X_{i j}$ be the lifetime of component $j$ in $i$ th subsystem, which is an uncertain variable defined on the uncertainty space $\left(\Gamma_{i j}, L_{i j}, M_{i j}\right), i=1,2, \ldots, m, \quad j=1,2, \ldots, n$. Suppose $X_{i j}, i=1,2, \ldots, m, j=1,2, \ldots, n$ be independent mutually. The lifetime of the parallel-series system is $\mathrm{X}=\min _{1 \leq i \leq m}\left(\max _{1 \leq j \leq n} \mathrm{X}_{i j}\right)$, which is also an uncertain variable on the product uncertainty space $(\Gamma, \mathrm{L}, \mathrm{M}), \quad$ where $\quad \Gamma=\Gamma_{11} \times \Gamma_{12} \times \cdots \times \Gamma_{m n}, \quad \mathrm{~L}=\mathrm{L}_{11} \times \mathrm{L}_{12} \times \cdots \times \mathrm{L}_{\mathrm{mn}} \quad$ and $\mathrm{M}=\mathrm{M}_{11} \wedge \mathrm{M}_{12} \wedge \cdots \wedge \mathrm{M}_{\mathrm{mn}}$.

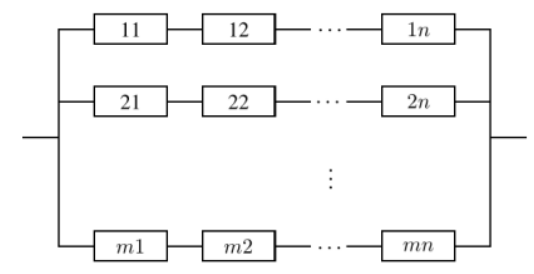

\section{Figure 6. A Parallel-Series System}

Theorem 9 The reliability of the parallel-series system is

$$
R(t)=\underset{i=1}{\wedge} \underset{j=1}{\vee} M\left\{X_{i j}>t\right\} .
$$

Theorem 10 The MTTF of the parallel-series system is

$$
\mathrm{MTTF}=\hat{\mathrm{i}=1}_{\mathrm{j}=1}^{\mathrm{n}} \mathrm{V} \mathrm{E}\left[\mathrm{X}_{\mathrm{ij}}\right] .
$$

\section{Conclusions}

Using probability theory to deal with reliability problems, the lifetimes of systems or components are required to follow certain probability distributions. However, in many real-world applications, the lifetimes of systems or components may only be characterized subjectively. Uncertainty theory is a branch of mathematics of studying the subjective uncertain behavior. The superiority of uncertain measure is that it has the properties of normality, duality and subadditivity. The main contribution of the paper is to make reliability analysis of unrepairable systems by using uncertainty theory. In further research, we can use uncertainty theory to deal with repairable systems about reliability problems or other fields related to subjective uncertainty.

\section{Acknowledgments}

This work was supported by the National Natural Science Foundation of China Grant No. 11301382, No. 61070021 and No. 61272509. 


\section{References}

[1] R. E. Barlow and F. Proschan, "Mathematical Theory of Reliability", John Wiley \& Sons, Inc., New York, 1965.

[2] R. E. Barlow, F. Proschan, Statistical Theory of Reliability and Life Testing: Probability Models, Holt, Rinehart and Winston, 1975.

[3] K. Cai, C. Wen, M. Zhang, Fuzzy variables as a basis for a theory of fuzzy reliability in the possibility context, Fuzzy Sets and Systems 42 (1991) 145-172.

[4] K. Cai, C. Wen, M. Zhang, Posbist reliability behavior of fault-tolerant systems, Microelectronics and Reliability 35 (1995) 49-56.

[5] K. Cai, C. Wen, M. Zhang, Posbist reliability behavior of typical system with two types of failures, Fuzzy Sets and Systems 43 (1991) 17-32.

[6] K. Cai, C. Wen, M. Zhang, Fuzzy states as a basis for a theory of fuzzy reliability, Microelectronics and Reliability 33 (1993) 2253-2263.

[7] M. Chao and J. Fu, The reliability of a large series system under Markov structure, Advances in Applied Probability 23(4) (1991) 894-908.

[8] S. K. Chhillar, A. K. Barak, S. C. Malik, Analysis of a parallel system with priority to maintenance over repair subject to random shocks, American Journal of Mathematics and Statistics 3(5) (2013) 258-264.

[9] W. K. Chung, Reliability analysis of a series repairable system with multiple failures, Microelectronics and Reliability 31(2-3) (1991) 371-373.

[10] Y. Ding, A. Lisnianski, Fuzzy universal generating functions for multi-state system reliability assessment, Fuzzy Sets and Systems 159 (2008) 307-324.

[11] L. R. Goel, R. Gupta, S. K. Singh, Availability analysis of a two-unit (dissimilar) parallel system with inspection and bivariate exponential lifetimes, Microelectronics Reliability 25(1) (1985) 77-80.

[12] ] S. V. Gurov and L. V. Utkin, A new method to compute reliability of repairable series systems by arbitrary distributions, Microelectronics and Reliability 35(1) (1995) 81-85.

[13] S. Han, Z. Peng and S. Wang, The maximum flow problem of uncertain network, Information Sciences 265(1) (2014) 167-175.

[14] H. Huang, Reliability analysis method in the presence of fuzziness attached to operating time, Microelectronics and Reliability 35 (1995) 1483-1487.

[15] A. Kaufman, Introduction to the Theory of Fuzzy Subsets, Volume 1, New York: Academic Press, 1975.

[16] ] Z. Khalil, Availability of series systems with various shut-off rules, IEEE Transactions on Reliability 34(2) (1985) 187-189.

[17] X. Li, B. Liu, Hybrid logic and uncertain logic, Journal of Uncertain Systems 3(2) (2009) 83-94.

[18] Y. Li, K. Tao, R. V. Leon, F. M. Guess, Estimation of error from treating travel time as additional repair time, IEEE Transactions on Reliability 60(2) (2011) 441-447.

[19] B. Liu, Uncertainty Theory, 2nd edn, Springer-Verlag, Berlin, 2007.

[20] B. Liu, Some research problems in uncertainty theory, Journal of Uncertain Systems 3(1) (2009) 3-10.

[21] B. Liu, Uncertainty Theory: A Branch of Mathematics for Modeling Human Uncertainty, SpringerVerlag, Berlin, 2010.

[22] B. Liu, Uncertain risk analysis and uncertain reliability analysis, Journal of Uncertain Systems 4(3) (2010) 163-170

[23] Y. Liu, H. Huang, G. Levitin, Reliability and performance assessment for fuzzy multi-state elements, Journal of Risk and Reliability 222 (2008) 675-686.

[24] Y. Liu, G. Yang, G. Xu, Uncertain structural properties and reliability analysis of coherent systems based on uncertain states, Journal of Information \& Computational Science 7(13) (2010) 2573-2580.

[25] Y. Liu, W. Tang, X. Li, Random fuzzy shock models and bivariate random fuzzy exponential distribution, Applied Mathematical Modelling 35 (2011) 2408-2418.

[26] Y. Liu, H. Zhu, Reliability analysis of fuzzy unrepairable systems, Information: An International Interdisciplinary Journal 15 (2012) 3935-3944.

[27] S. Osaki, S. Yamada, J. Hishitani, Availability theory for two-unit nonindependent series systems subject to shut-off rules, Reliability Engineering and System Safety 25(1) (1989) 33-42.

[28] V. Sridharan, P. Mohanavadivu, Reliability and availability analysis for two non-identical unit parallel systems with common cause failures and human errors, Microelectronics Reliability 37(5) (1997) 747752.

[29] D. Tian, L. Wang, J. Wu, M. Ha, Rough set model based on uncertain measure, Journal of Uncertain Systems 3(4) (2009) 252-256.

[30] L. Utkin, S. Gurov, A general formal approach for fuzzy reliability analysis in the possibility context, Fuzzy Sets and Systems 83 (1996) 203-213

[31] J. Zhang, R. Zhao, W. Tang, Fuzzy age-dependent replacement policy and SPSA algorithm based on fuzzy simulation, Information Sciences 178 (2008) 573-583. 